\title{
Retention in HIV Care among Children Aged 0-14 Years and the Associated Family and Caregiver Factors in Embu County, Kenya
}

\author{
Ikiara, Eliza Kathure ${ }^{1}$, Orinda, George Owino ${ }^{2}$, Thigiti, Joseph Mwangi ${ }^{3}$ \\ ${ }^{1}$ MPH Candidate, Department of Community Health and Epidemiology, School of Public Health, Kenyatta \\ University. P.O Box 43844 -00100, Nairobi, Kenya. \\ ${ }^{2}$ Senior Lecturer, Department of Biochemistry and Biotechnology, School of Pure and Applied Sciences, \\ Kenyatta University. P.O Box $43844-00100$, Nairobi, Kenya. \\ ${ }^{3}$ Senior Lecturer, Department of Obstetrics and Gynaecology (Family Medicine Programme), School of \\ Medicine, Kenyatta University. P.O Box 43844 -00100, Nairobi, Kenya.
}

Corresponding Author: Ikiara, Eliza Kathure

\begin{abstract}
Background: Retention of children in HIV care is influenced by a number of factors, among them family and caregiver factors.

Objective: To determine the family and caregiver factors associated with retention in care.

Methods: We conducted a cross sectional study in level 4 and 5 hospitals in Embu county. Data were collected through interviews using a predesigned questionnaire. Descriptive and inferential data analysis was performed.

Results: We enrolled 238 participants between January and April 2018, comprising 143 males $(50.5 \%)$ and 140 females (49.5\%). The median age of the participants was 12 years (IQR 5). Two thirds of the minors were in primary school $(192,67.8 \%)$. More of the children's mothers were HIV positive compared to the fathers ( 257 vs 99 ) though a greater number of the fathers had an unknown HIV status compared to the mothers (138 vs 21$)$. Most minors $(241,85.2 \%)$ were retained in care throughout having never missed an appointment. The number of siblings alive (aOR $0.72,95 \% \mathrm{CI}$ : $0.56,0.92$ ), siblings with HIV (aOR $0.26,95 \%$ CI: 0.10, 0.68), a HIV positive caregiver (aOR 5.48, $95 \%$ CI: $2.44,12.97$ ), stigma (aOR 0.35, 95\% CI: $0.15,0.77$ ), work duties of the caregiver (aOR 0.28 , $95 \% \mathrm{CI} 0.13,0.58$ ) and denial of HIV status by the caregiver (aOR $0.10,95 \%$ CI $0.02,0.47$ ) were all associated with retention in HIV care.

Conclusion: A HIV positive caregiver was most likely to ensure a child is retained in care. Stigma and denial of HIV status still hinder retention.
\end{abstract}

Key Words: Retention, HIV, children, caregiver

\section{INTRODUCTION}

Diagnosis and retention of HIVexposed and infected children in care presents unique challenges to healthcare systems in resource limited settings. This challenge is complicated by the dependence of the minors upon a caregiver. ${ }^{[1]}$ As of 2020, 1.7 million children under the age of 15 were living with HIV globally, $90 \%$ of these children were resident in sub-Saharan
Africa. ${ }^{[2]}$ In Kenya, the Ministry of Health estimates that 139,000 children were living with HIV in 2018. This constitutes $10 \%$ of all the people living with HIV in Kenya. ${ }^{[3]}$ In Embu County, 855 were children aged between 0 to 14 years were living with HIV. ${ }^{[4]}$

Retention in care can be defined from the moment of initial engagement in care, when a person with HIV is linked 
successfully to services, to assessment for eligibility, initiation on ART (antiretroviral therapy) and retention in lifelong ART care. ${ }^{[1]}$ It can also be defined as the proportion of children known to be alive and attending care at their initiation facility. ${ }^{[5]}$ Retention in HIV care includes both those PLHIV (People living with HIV) on pre-ART care and those on ART care. For patients on ART, retention in care helps prevent medication interruptions, maintains immunologic benefits, prevents HIV resistance, and also monitors the effects of therapy. For those patients who have not yet been initiated on ART (pre-ART care), continuous monitoring is needed to prevent development of advanced disease. Additionally, all patients benefit from the secondary prevention messages, counselling, and other ancillary services provided at regular medical visits. ${ }^{[6]}$ It is now recognized that poor retention of patients in care, especially in the pre-ART period, is a major driver of poor HIV programme performance and increased morbidity and mortality. ${ }^{[7,8]}$ There is an opportunity to provide other clinical services in the 'pre-ART' period such as interventions to reduce morbidity and mortality (e.g. co-trimoxazole (CTX) prophylaxis, isoniazid preventive therapy (IPT)) and HIV prevention interventions. ${ }^{[1 \text {, }}$ 9]

In the United States, it is estimated that only $75 \%$ of HIV-diagnosed patients are linked to care, and only $66 \%$ of those linked to care are successfully retained in medical care. ${ }^{[7,10]}$ In a study done in Kenya, Tanzania, Rwanda and Mozambique, at 12 and 24 months, $80 \%$ and $72 \%$ of children were retained in care after ART initiation, with the lowest rate for children less than 1 year, with $51 \%$ at 24 months. ${ }^{[5]}$ In Kenya, retention in care at 12 months for those between 15 to 24 years is estimated at $68 \%$ with $75 \%$ for adults and $82 \%$ for children aged 10 to14 years. Retention in care at 36 months is at $66 \%$, whereas at 60 months, retention in care is at $61 \%$. ${ }^{[11]}$
It is crucial to understand the perspective and needs of caregivers as they relate to maintaining children in HIV care. [12] Caregiver characteristics such as health care seeking behaviours are often embedded in a network of competing priorities that include work and child care responsibilities. Other caregiver characteristics include limited perception of treatment issues, denial, alternative health beliefs and lack of disclosure to family. Community factors such as social stigma, remains a huge barrier to retention following HIV diagnosis and enrolment in care, especially for children who are orphaned. Financial challenges in providing ART services in resource-limited settings also affect retention when service charges are transferred to patients' families. In addition, challenges around transport to the clinic affect retention. ${ }^{[1]}$

Despite having good indicators on the prevention of mother to child transmission (PMTCT) of HIV, with maternal ART prophylaxis at 70\% in 2017 [13] and infant prophylaxis at 90\% in 2013, [14] care and treatment of children living with HIV in Embu County is still suboptimal. Viral suppression among children living with HIV in Embu County stands at $40 \%$. [4] Retention in care plays an important role in achieving viral suppression and there is a dearth of information on the retention in HIV care of children, especially those aged below 10 years. In Malawi, VLS (viral load suppression) was noted to be higher among children with optimal adherence to clinic appointments compared to the VLS of children with poor appointments adherence. [15]

Recognizing the role of family and caregivers in the continuum of HIV care for children, in particular retention in care, we designed and implemented a cross sectional study enrolling children aged $0-14$ years in Embu county. Our objective was to establish the family and caregiver factors that were associated with retention in care of children living with HIV in Embu County. 


\section{MATERIALS AND METHODS Study design and participants}

We conducted a cross sectional study among children living with HIV aged $0-14$ years enrolled for care in 4 hospitals within Embu County. Children who had a confirmed HIV diagnosis, either on pre ART or already were on treatment, were included in the study. Children below 18 months without a HIV RNA PCR (Ribonucleic Acid Polymerase Chain Reaction) test done to confirm HIV infection were excluded.

Data collection instruments included questionnaires and focus group discussion guide for the caregivers. Quantitative data was collected by interviewer administered structured questionnaires to the caregivers as well as older children (12-14 years) who assented. Recruitment was carried out on the specific paediatric clinic days. Qualitative data was collected via focus group discussions of caregivers. Chart reviews were carried out to determine those patients who had not been in contact for over 90 days since their last appointment (LTFU-lost to follow up), as well as, those who had defaulted on their clinic appointments. These patients were then traced by obtaining their personal contact information from the CCC (comprehensive care clinic) records as well as collaboration with CHEWs (community health extension workers). Once they were located, the questionnaire was administered to them, after their consent, at the CCC.

Approval to conduct the study was obtained by KU (Kenyatta University) Graduate School (Q57/27657/2014). Ethical clearance was sought from KUERC (Kenyatta University Ethics Review Committee) (KU/ERC/APPROVAL/VOL.1 (108)). Authority was sought from NACOSTI (National Commission for Science, Technology and Innovation) (NACOSTI/P/18/12074/19057). Permission was obtained from the Embu County Health Office and the health facility heads (ECH/ADM/17/VOL./). The caregivers gave consent, while the older children (12-
14 years) gave assent before participating. The study had no risks or financial benefits and was used for academic purposes. Confidentiality was ensured by use of coding during data processing.

\section{Statistical analysis}

The calculated sample size was 301 using the Fischer et al. formula for sample size estimation. Probability-proportional-tosize sampling was used first to determine the sample size within each of the subcounties in Embu County (Manyatta, Runyenjes and Mbeere sub-counties). Secondly, purposive sampling was used to select the Level 4 and 5 public hospitals within the sub-counties (Embu level 5, Ishiara Level 4, Mbeere Level 4 and Runyenjes Level 4). Lastly, simple random sampling was used to select children living with HIV aged 0 to 14 years enrolled at the CCCs.

Data from the structured questionnaire was coded and entered into the Epi Info version 7 and thereafter, $\mathrm{R}$ software version 3.5.0 used for analysis. Descriptive statistics such as cross tabulation were used to establish the differences in causes, prevalence and effects. Pearson's correlation coefficient (r) was used to determine the strength and direction of associations between the variables. Trends that emerged were presented in charts, graphs, and tables. Pearson's Chi Square test was used to show statistical significance of relationships in data.

\section{RESULTS}

Between January and April 2018, we enrolled 283 participants. The participants were roughly equally distributed by sex (140 females, $49.5 \%$ ) with a median age of 12 years (IQR 5) (Table 1). A larger proportion of the children were in primary school (192(67.8\%)) with an almost equal number living with their parent(s) $(191(67.5 \%))$. Slightly more than half $(167(59 \%))$ of the children's caregivers were engaged in farming as their main 
source of income. It was found that $88 \%$ of the children enrolled in care were reported to have HIV negative siblings, and of those siblings who were HIV positive, $97 \%$ were enrolled in care as well.

Regarding the children's parents and their HIV status, there were more mothers who were reported to be HIV positive compared to the fathers ( 257 vs. 99), but a larger number of fathers had an unknown HIV status compared to mothers (138 vs. 21). These differences were statistically significant (Pearson's Chi-squared test $=$ 189.2, $\mathrm{df}=2, \mathrm{p}<0.001)$. A larger number of mothers who were HIV positive were enrolled in care compared to HIV positive fathers (186 vs. 63), and this difference was statistically significant (Fisher's Exact Test, $\mathrm{p}=0.03$ ).

Most caregivers reported that the children attended their CCC appointments consistently $(n=241,85.2 \%)$. Of those who failed to attend the clinic consistently $(n=42$, $14.8 \%$ ), two thirds had missed their appointments for less than three months (defaulters) while the remaining third had gone missing for more than three months and could be termed as lost to follow up (LFTU). The most common reason why children missed clinic appointments was that their caregivers were too busy $(n=17$, 6\%) (Figure 1).

Mothers accompanied the children to the clinic in half the reports $(n=142,50.2 \%)$, but in some cases, the children attended the appointments on their own $(n=57,20.1 \%)$ (Table 2). Those children who attended the clinic on their own were older compared to the other children who were accompanied (median age in years $=14$, IQR 0 ).

In ninety four percent of the cases, the extended family members were aware of the child's HIV status. Also, two thirds of the caregivers were HIV positive as well. Similarly, for most of the HIV positive caregivers, their extended family members were aware of their status $(n=174(92.6 \%))$. All HIV positive caregivers were enrolled in care themselves and only 12 (6.4\%) had ever stopped attending the clinic at some point. Of these 12 caregivers, $5(41.7 \%)$ had been lost to follow up for more than 3 months at some point.

Only $3.9 \%$ of the caregivers reported to have used alternative medicine to manage the child's HIV infection. Two thirds of the caregivers cited financial challenges while seeking HIV care for the child. During the focus group discussions, one caregiver reported that "Transport fare sometimes is lacking, so we have to walk to hospital. Money for food, as well, sometimes is hard to come by." Another said "Motorbikes are the only available transport means from my home. Sometimes, I do not have money for transport fare." Stigma due to the child's HIV status was also a challenge while seeking HIV care. $(\mathrm{n}=160,56.5 \%)$. A caregiver remarked that "We fear discrimination by the child's age mates if they find out his HIV status."

Six caregiver/family factors were significantly associated with retention in care during bivariate analysis (Table 3 ). Only one variable; the caregiver being HIV positive and possibly enrolled in care, increased the odds of being retained in care (cOR $=2.84,95 \% \mathrm{CI}$; (1.45, 5.57), $\mathrm{p}=0.002$ ). The remaining five factors conferred lower odds of being retained in care. These were; being accompanied to the clinic by either a sibling (cOR $=0.04,95 \%$ CI: $(0.004,0.45)$, $\mathrm{p}=0.009$ ) or another relative (aunt, uncle, grandparent $)$ (cOR $=0.42,95 \%$ CI: $(0.19$, 0.93), $\quad \mathrm{p}=0.03), \quad$ work/child care responsibilities of the caregiver $(\mathrm{cOR}=$ $0.33,95 \%$ CI: $(0.17,0.65), \mathrm{p}=0.002)$, lack of belief in the benefits of ARVs (cOR = $0.15,95 \%$ CI: $(0.05,0.51), \mathrm{p}=0.002)$ and denial of child's HIV status by the caregiver $(\mathrm{cOR}=0.16,95 \% \mathrm{CI}:(0.04,0.68), \mathrm{p}=0.01)$.

Six caregiver/family factors were significantly associated with retention in care in the parsimonious model (Table 4). The caregiver being HIV positive and possibly enrolled in care, increased the odds of being retained in care $(\mathrm{aOR}=5.48,95 \%$ CI $(2.44,12.97), \mathrm{p}<0.001)$. The other five variables lowered the odds of being retained in care. Having an additional sibling 
Ikiara, Eliza Kathure et.al. Retention in HIV care among children aged 0-14 years and the associated family and caregiver factors in Embu County, Kenya.

reduced the odds of being retained in care by 0.72 times $(95 \%$ CI $(0.56,0.92), p$ $=0.01)$.

We estimate that the odds of a HIV positive child, whose sibling was also HIV positive, being retained in care was 0.26 times that of a HIV positive child without a sibling of similar status, with the former, thereby, having lower odds $(\mathrm{aOR}=0.26$, $95 \%$ CI $\quad(0.10, \quad 0.68), \quad \mathrm{p}=0.01)$. Discrimination against the caregiver and HIV positive child was estimated to lower the odds of retention in care by 0.35 compared to those who were not discriminated against $(\mathrm{aOR}=0.35,95 \% \mathrm{CI}$ $(0.15,0.77), \mathrm{p}=0.01)$.

The odds of retention in care in children of caregivers who had a lot of responsibilities at work or at home was estimated to be 0.28 times that of children whose caregivers did not have work or home related responsibilities $(\mathrm{aOR}=0.28$, $95 \%$ CI $(0.13,0.58), p<0.001)$. Caregivers who were in denial of their child's HIV status were estimated to have 0.10 times the odds of having their child retained in care compared to those who had accepted the child's status $(\mathrm{aOR}=0.10,95 \%$ CI $(0.02$, 0.47), 0.003).

\begin{tabular}{|c|c|c|}
\hline Variables & $\begin{array}{l}\text { Total } \\
(\mathrm{N}=283)\end{array}$ & $\%$ \\
\hline Sex & & \\
\hline Male & 143 & 50.5 \\
\hline Female & 140 & 49.5 \\
\hline Age in years; median IQR & $12(9-14)$ & \\
\hline \multicolumn{3}{|l|}{ Child's parents } \\
\hline \multicolumn{3}{|l|}{ Mother } \\
\hline \multicolumn{3}{|l|}{ Alive; $\mathrm{n}(\%)$} \\
\hline Yes & 193 & 68.2 \\
\hline No & 90 & 31.8 \\
\hline \multicolumn{3}{|l|}{ HIV status: $\mathrm{n}(\%)$} \\
\hline Negative & 5 & 1.8 \\
\hline Positive & 257 & 90.8 \\
\hline Unknown & 21 & 7.4 \\
\hline \multicolumn{3}{|l|}{ Father } \\
\hline \multicolumn{3}{|l|}{ Alive: $\mathrm{n}(\%)$} \\
\hline Yes & 203 & 71.7 \\
\hline No & 80 & 28.3 \\
\hline \multicolumn{3}{|l|}{ HIV status: n(\%) } \\
\hline Negative & 46 & 16.3 \\
\hline Positive & 99 & 35.0 \\
\hline Unknown & 138 & 48.8 \\
\hline \multicolumn{3}{|l|}{ Details of siblings } \\
\hline $\begin{array}{l}\text { Number of other children in the family: } \\
\text { median (IQR) }\end{array}$ & $3(2-4)$ & \\
\hline $\begin{array}{l}\text { Age of the eldest child in years: mean } \\
\text { (SD) }\end{array}$ & $19.7( \pm 7.6)$ & \\
\hline $\begin{array}{l}\text { Age of youngest child in years: median } \\
\text { (IQR) }\end{array}$ & $9(5-13)$ & \\
\hline \multicolumn{3}{|l|}{ Other sibling living with HIV: $\mathrm{n}(\%)$} \\
\hline Yes & 32 & 11.3 \\
\hline No & 251 & 88.7 \\
\hline \multicolumn{3}{|l|}{$\begin{array}{l}\text { HIV positive sibling enrolled in CCC: } \\
\mathrm{n}(\%)\end{array}$} \\
\hline Yes & 31 & 11.0 \\
\hline No & 1 & 0.4 \\
\hline N/A(sibling not HIV positive) & 251 & 88.7 \\
\hline \multicolumn{3}{|l|}{ Child's place of residence: $n(\%)$} \\
\hline Relative & 88 & 31.1 \\
\hline Parents & 191 & 67.5 \\
\hline Children's' home & 3 & 1.1 \\
\hline Foster parent & 1 & 0.4 \\
\hline
\end{tabular}

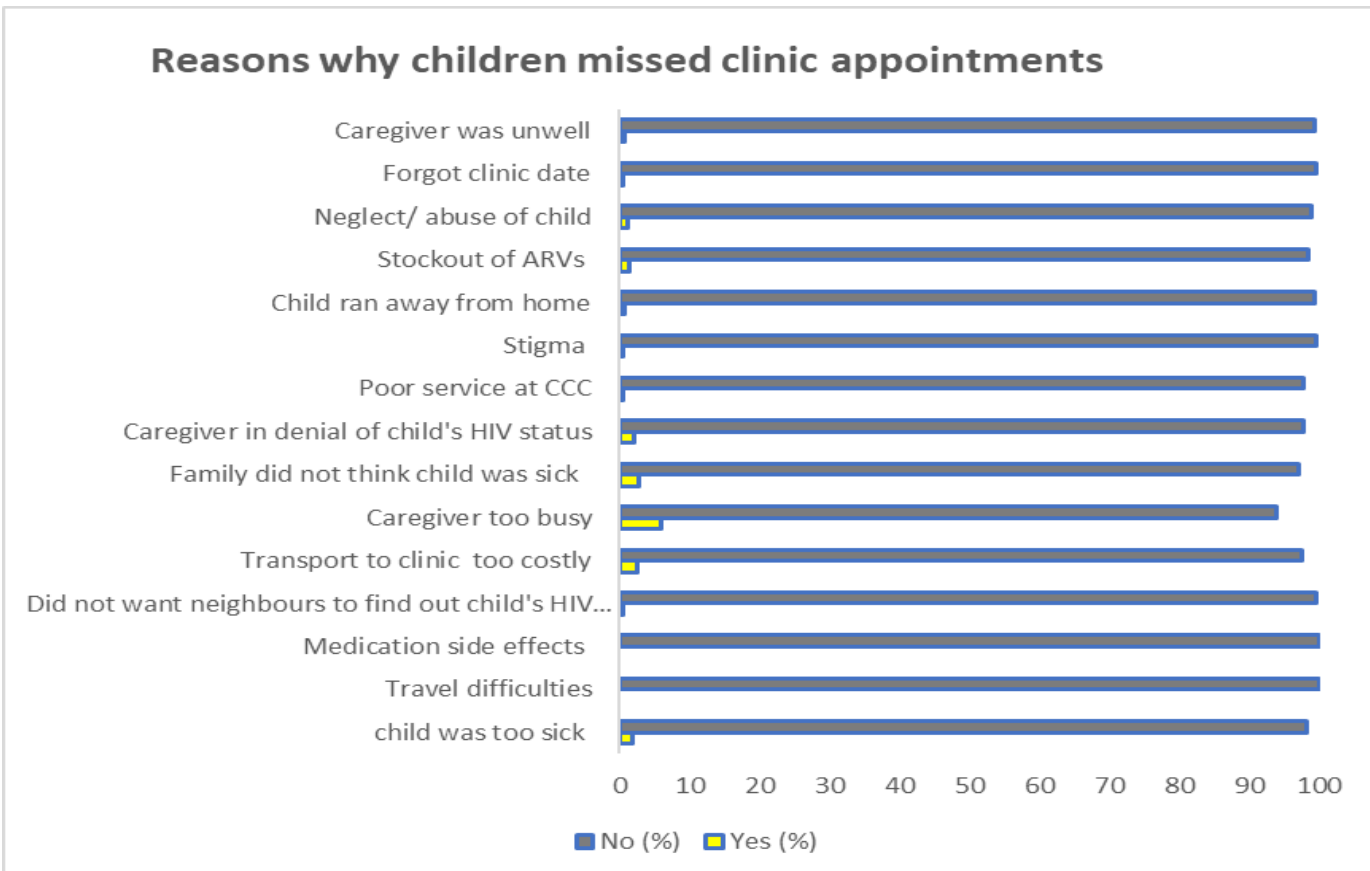

Figure 1: Reasons why participants missed clinic appointments 
Ikiara, Eliza Kathure et.al. Retention in HIV care among children aged 0-14 years and the associated family and caregiver factors in Embu County, Kenya.

Table 2: Caregiver/family factors related to retention in care

\begin{tabular}{|c|c|c|}
\hline Variable & Yes $(\mathrm{n}(\%))$ & No $(\mathbf{n}(\%))$ \\
\hline Caregiver who takes the child to the clinic: $\mathrm{n}(\%)$ & & \\
\hline Mother & $142(50.2)$ & \\
\hline Father & $11(3.9)$ & \\
\hline Sibling & $4(1.4)$ & \\
\hline Relative & $65(23.0)$ & \\
\hline Grandparent & $42(14.8)$ & \\
\hline Aunt & $18(6.4)$ & \\
\hline Uncle & $2(0.7)$ & \\
\hline Step parent & $2(0.7)$ & \\
\hline Cousin & - & \\
\hline Great grandparent & $1(0.4)$ & \\
\hline Self & $57(20.1)$ & \\
\hline Children's home employee & $3(1.1)$ & \\
\hline Foster parent & $1(0.4)$ & \\
\hline Extended family members aware of child's HIV status & $264(93.3)$ & $19(6.7)$ \\
\hline Child's caregiver HIV positive? & $188(66.4)$ & $95(33.6)$ \\
\hline Extended family aware of caregiver's status & $174(92.6)$ & $14(7.4)$ \\
\hline Caregiver enrolled in care? & $188(100)$ & - \\
\hline Attended last clinic? & $182(96.8)$ & $6(3.2)$ \\
\hline Ever stopped attending clinic? & $12(6.4)$ & $176(95.6)$ \\
\hline Period of missed clinics; $\mathrm{n}(\%)$ & & \\
\hline$<3$ months & $7(58.3)$ & \\
\hline 3 months & $5(41.7)$ & \\
\hline Use of alternative medicine by caregiver to treat child & $11(3.9)$ & $272(96.1)$ \\
\hline Challenges experienced while bringing the child to the clinic; & & \\
\hline Stigma due to the child's HIV status & $160(56.5)$ & $123(43.5)$ \\
\hline Work/childcare responsibilities of the caregiver & $81(28.6)$ & $202(71.4)$ \\
\hline Lack of support by male family members & $102(36.0)$ & $181(64.0)$ \\
\hline No belief in the benefit of ARVs & $12(4.2)$ & $271(95.8)$ \\
\hline Lack of transport to the $\mathrm{CCC}$ & $85(30.0) 184(65.0)$ & $198(70.0)$ \\
\hline Financial constraints in seeking HIV care & $9(3.2)$ & $99(35.0)$ \\
\hline Abandonment/neglect of the child & $8(2.8)$ & $274(96.8)$ \\
\hline Denial of HIV status & $2(0.7)$ & $275(97.2)$ \\
\hline Caregiver was unwell & & $281(99.3)$ \\
\hline
\end{tabular}

Table 3: Bivariable and multivariable logistic regression analysis of caregiver/family factors

\begin{tabular}{|c|c|c|c|c|c|c|}
\hline Variable & Crude OR & $95 \%$ CI $(\mathrm{L}, \mathrm{H})$ & p value & Adjusted OR & $95 \%$ CI $(L, H)$ & p value \\
\hline Number of siblings who are alive & 0.84 & $0.68,1.02$ & 0.08 & 0.73 & $0.55,0.97$ & 0.03 \\
\hline Another sibling with HIV & 0.27 & 0.12 .0 .62 & 0.002 & 0.44 & 0.14 .1 .46 & 0.16 \\
\hline $\begin{array}{l}\text { Who does the child live with } \\
\text { Relative (reference) } \\
\text { Parent (s) } \\
\text { Children's home } \\
\text { Foster parents }\end{array}$ & $\begin{array}{l}1 \\
2.12 \\
0.56 \\
-\end{array}$ & $\begin{array}{l}1.07,4.19 \\
0.05,6.59 \\
-\end{array}$ & $\begin{array}{l}<0.001 \\
0.03 \\
0.64 \\
<0.001\end{array}$ & $\begin{array}{l}1 \\
0.67\end{array}$ & $0.90,5.04$ & 0.69 \\
\hline $\begin{array}{l}\text { Occupation of the caregiver } \\
\text { Casual laborer (reference) } \\
\text { Farmer } \\
\text { Formal employment } \\
\text { Self employed } \\
\text { Children's home employee } \\
\text { Retired }\end{array}$ & $\begin{array}{l}1 \\
1.06 \\
2.24 \\
1.66 \\
0.39 \\
- \\
\end{array}$ & $\begin{array}{l}0.43,2.55 \\
0.43,11.76 \\
0.45,6.10 \\
0.30,5.03 \\
-\end{array}$ & $\begin{array}{l}<0.001 \\
0.90 \\
0.34 \\
0.45 \\
0.47 \\
<0.001\end{array}$ & $\begin{array}{l}1 \\
0.83 \\
1.08 \\
1.40\end{array}$ & $\begin{array}{l}0.21,2.76 \\
0.16,9.56 \\
0.23,9.06\end{array}$ & $\begin{array}{l}0.78 \\
0.94 \\
0.71\end{array}$ \\
\hline $\begin{array}{l}\text { Person who accompanies child to the clinic } \\
\text { Mother (reference) } \\
\text { Father } \\
\text { Sibling } \\
\text { Relative } \\
\text { Self } \\
\text { Children's home employee } \\
\text { Foster parents }\end{array}$ & $\begin{array}{l}1 \\
1.27 \\
0.04 \\
0.42 \\
1.08 \\
0.254 \\
- \\
\end{array}$ & $\begin{array}{l}0.15,10.97 \\
0.004,0.45 \\
0.19,0.93 \\
0.39,2.96 \\
0.02,3.09 \\
-\end{array}$ & $\begin{array}{l}<0.001 \\
0.83 \\
0.009 \\
0.03 \\
0.88 \\
0.28 \\
<0.001\end{array}$ & $\begin{array}{l}1 \\
6.79 \\
0.17 \\
1.15 \\
1.61\end{array}$ & $\begin{array}{l}0.57,187.37 \\
0.004,5.19 \\
0.15,9.06 \\
0.42,7.80\end{array}$ & $\begin{array}{l}0.17 \\
0.33 \\
0.89 \\
0.51\end{array}$ \\
\hline Extended family aware of child's status & 0.30 & $0.04,2.36$ & 0.25 & 0.50 & $0.02,3.30$ & 0.54 \\
\hline Child's caregiver HIV positive & 2.84 & $1.45,5.57$ & 0.002 & 6.84 & $1.37,38.30$ & 0.02 \\
\hline Alternative medicine for HIV & - & - & $<0.001$ & 0 & - & \\
\hline $\begin{array}{l}\text { Challenges while bringing the child to the clinic; } \\
\text { Stigma due to the child's HIV status } \\
\text { Work/childcare responsibilities } \\
\text { Lack of support by male family members } \\
\text { No belief in the benefit of ARVs } \\
\text { Lack of transport to the CCC } \\
\text { Financial constraints in seeking HIV care } \\
\text { Abandonment/neglect of the child } \\
\text { Denial of HIV status } \\
\text { Caregiver was unwell }\end{array}$ & $\begin{array}{l}0.53 \\
0.33 \\
0.64 \\
0.15 \\
1.45 \\
1.04 \\
- \\
0.16 \\
0.17\end{array}$ & $\begin{array}{l}0.26,1.08 \\
0.17,0.65 \\
0.33,1.24 \\
0.05,0.51 \\
0.67,3.11 \\
0.52,2.07 \\
- \\
0.04,0.68 \\
0.01,2.85\end{array}$ & $\begin{array}{l}0.08 \\
0.002 \\
0.18 \\
0.002 \\
0.34 \\
0.91 \\
<0.001 \\
0.01 \\
0.22\end{array}$ & $\begin{array}{l}0.30 \\
0.20 \\
0.90 \\
0.12 \\
2.27 \\
0.75 \\
0.30 \\
0.06\end{array}$ & $\begin{array}{l}0.11,0.75 \\
0.08,0.47 \\
0.36,2.30 \\
0.01,1.42 \\
0.85,6.70 \\
0.27,1.98 \\
0.01,5.85 \\
0.002,1.82\end{array}$ & $\begin{array}{l}0.01 \\
<0.001 \\
0.82 \\
0,08 \\
0.12 \\
0.57 \\
0.42 \\
0.07\end{array}$ \\
\hline
\end{tabular}


Ikiara, Eliza Kathure et.al. Retention in HIV care among children aged 0-14 years and the associated family and caregiver factors in Embu County, Kenya.

Table 4: Parsimonius model with caregiver/family factors

\begin{tabular}{|l|l|l|l|}
\hline Variable & Adjusted OR & $\mathbf{9 5 \%}$ CI(L, H) & p value \\
\hline Number of siblings who are alive & 0.72 & $0.56,0.92$ & 0.01 \\
\hline Another sibling with HIV & 0.26 & $0.10,0.68$ & 0.01 \\
\hline Child's caregiver HIV positive & 5.48 & $2.44,12.97$ & $<0.001$ \\
\hline Challenges while bringing child to the clinic $;$ & & & \\
Stigma due to the child's HIV status & 0.35 & $0.15,0.77$ & 0.01 \\
Work/childcare responsibilities & 0.28 & $0.13,0.58$ & $<0.001$ \\
Denial of HIV status & 0.10 & $0.02,0.47$ & 0.003 \\
Caregiver was unwell & 0.07 & $0.002,2.50$ & 0.11 \\
\hline
\end{tabular}

\section{DISCUSSION}

In this cross-sectional study exploring the family and caregiver factors associated with retention in care among children aged $0-14$ years old, we identified several covariates. The number of siblings alive, having another sibling and or the caregiver with HIV, challenges with coming (transport) to the clinic, stigma, work / childcare responsibilities, denial of HIV status and having a caregiver who was unwell were all associated with retention in HIV care.

We found that $67.5 \%$ of the caregivers were the biological parents, while $14.8 \%$ were the grandmothers of the children. This relates to a study done in Uasin Gishu County in 2012, [16] which found that $77 \%$ of the caregivers were biological parents while $11.5 \%$ were the grandmothers. In our study, we found that majority of the caregivers $(59 \%)$ were farmers, followed by $17.3 \%$ who were casual labourers. However, in the study by Wachira et al, [16] majority $(38 \%)$ were casual labourers, followed by $27 \%$ who had no occupation and $23 \%$ who were farmers. Our study was in a mainly rural setting which explains the predominance of farming as the caregivers' occupation. The study by Wachira et al ${ }^{[16]}$ combined both rural and urban settings which may explain the heterogeneity of caregivers' occupations.

Notably, $88.7 \%$ of the children did not have a HIV positive sibling, meaning they were the only child in the family living with HIV. We found that $56.5 \%$ of the respondents reported fear of, and/or experiencing stigma from family members / community while seeking HIV care for the child. This relates well with the findings of the National HIV and AIDS stigma and discrimination Index survey done in 2014, which report that the stigma index in Embu County stands at $49.2 \%$. Nationally, it is reported as $45 \%$. ${ }^{[17]}$ Our study found that the respondents who reported stigma had 0.35 lesser odds of being retained in care. This relates well with a study done in Western Kenya, where among the HIVpositive children, $16 \%$ had not returned to clinic because of disclosure issues/ discrimination in the family or community. [18] Stigma and fear of disclosure have been cited as factors that may affect an individual's ability to access and remain in HIV care in USA. ${ }^{[19]}$ In addition, a study done in Tanzania revealed that $50 \%$ of caregivers and $55 \%$ of adolescents stated that stigma is a barrier to retention in HIV care and treatment. ${ }^{[20]}$

Our study found that $65 \%$ of the respondents cited financial constraints (such as transport fare, money for food) as a major challenge while accessing HIV care. Wachira et al ${ }^{[16]}$ noted that in all their study respondents, financial constraints were expressed as a key barrier. A study in Uganda revealed that caregivers experienced a challenge of the logistics of bringing the child to the clinic such as transport and food. ${ }^{[21]}$ In Nigeria, 25\% of caregivers of children lost to follow up cited financial constraints, such as inability to meet up with cost of transportation and ancillary investigations. ${ }^{[22]}$

Our study concluded that having an additional sibling with HIV led to 0.26 times lesser odds of retention in care. This concurs with Wachira et al ${ }^{[16]}$ who found out that caregivers who had more than one HIV infected or HIV exposed child faced greater challenges following the difficulty 
of carrying two to three children to the clinic without any help.

We found that the children who were accompanied by a relative (aunt, uncle, grandparent), as opposed to the biological parent, to the clinic had 0.42 times lower odds of retention in care. This relates with a study in Nigeria that found that children whose primary caregiver was an extended family member as opposed to the parent(s) or an elder sibling, had higher rates of attrition (LTFU or death). ${ }^{[22]}$ This is in contrast to a study done by Sengayi et al ${ }^{[23]}$ in South Africa that concluded that children whose primary caregiver was the biological mother had a higher risk of LTFU. Sengayi [23] attributed his findings to the possibility of death of the mothers during the study period. Caregivers in Uganda noted that the children need parental support and they should accompany them to the clinic for their appointments. ${ }^{[21]}$

Also, work / child care responsibilities led to a 0.28 lesser odds of retention among our respondents. This concurs with a study done in Uganda in 2010, which identified work responsibilities in $27 \%$ and child care commitments in $22 \%$ of their respondents as reasons for not returning to the clinic. ${ }^{[24]}$ Nasuuna et al, in Uganda, found that caregivers of HIV positive children stated that competing factors such as employment or looking for food was a challenge in accessing care. ${ }^{21]}$

The caregiver being HIV positive was significantly associated with 5.48 higher odds of retention in care. This relates well with a study done in South Africa in 2007 which found that having a HIV positive caregiver was a protective factor against mortality among HIV positive children on ART. ${ }^{[25]}$

The County Government (Health department) in partnership with the National Government (Ministry of Health) and Non Governmental Organisations should conduct regular, wide scale campaigns and public forums to educate the general public about non-discrimination against PLHIV. This will, in turn, foster acceptance of PLHIV, reduce the deterrents towards disclosure of one's HIV status and improve retention in care.

It would be worthwhile to conduct a study to ascertain why the HIV status of a large number of fathers of the children was unknown to the respondents (mainly mothers). The study would determine if lack of HIV testing by male partners or lack of disclosure of one's HIV status by male partners are behind this occurrence. Also, a comprehensive study to unravel the sociocultural reasons behind the high level of stigma against PLHIV in Embu County is warranted.

\section{CONCLUSION}

Majority of the caregivers were the biological parents. Most of them earned a living through farming. Two thirds of the respondents cited financial constraints as a caregiver/family factor that posed a challenge. Slightly over half reported stigma as well. Notably $66 \%$ of the caregivers were, themselves, also HIV positive. The caregiver being HIV positive was significantly associated with higher odds of retention in care. Stigma, work/child care responsibilities, denial of child's HIV status, lack of belief in benefit of ARVs, child having a HIV positive sibling and caregiver being a relative (apart from parent) were significantly associated with lower odds of retention.

\section{ACKNOWLEDGEMENTS}

I wish to thank the Embu County Health Office and the health facility heads of the four hospitals I visited, namely Embu Level 5, Runyenjes Level 4, Ishiara Level 4 and Mbeere Level 4. I am grateful to my study respondents for their cooperation and the CCC health workers, working at the above named hospitals.

\section{Competing Interests}

The authors declare that they have no competing interests.

\section{Source of Funding: None}


Ikiara, Eliza Kathure et.al. Retention in HIV care among children aged 0-14 years and the associated family and caregiver factors in Embu County, Kenya.

\section{Ethical Approval: Approved}

\section{REFERENCES}

1. World Health Organization. Retention in HIV programmes: defining the challenges and identifying solutions: meeting report, 13-15 September 2011. WHO Press; 2012.

2. UNAIDS. UNAIDS Factsheet 2021. UNAIDS; 2021.

3. National AIDS and STI Control Programme (NASCOP). Preliminary Kenya Populationbased HIV Impact Assessment (KENPHIA) 2018 report. NASCOP; 2020.

4. National AIDS Control Council (NACC). Kenya HIV County profiles 2018. NACC; 2018.

5. McNairy ML, Lamb MR, Carter RJ, Fayorsey R, Tene G, Mutabazi V, et al. Retention of HIV-infected children on antiretroviral treatment in HIV care and treatment programs in Kenya, Mozambique, Rwanda, and Tanzania. J Acquir Immune Defic Syndr 1999. 2013 Mar 1;62(3):e7081.

6. Geng EH, Nash D, Kambugu A, Zhang Y, Braitstein P, Christopoulos KA, et al. Retention in care among HIV-infected patients in resource-limited settings: emerging insights and new directions. Curr HIV/AIDS Rep. 2010 Nov;7(4):234-44.

7. Gardner EM, McLees MP, Steiner JF, Del Rio C, Burman WJ. The spectrum of engagement in HIV care and its relevance to test-and-treat strategies for prevention of HIV infection. Clin Infect Dis Off Publ Infect Dis Soc Am. 2011 Mar 15;52(6):793800.

8. Rosen S, Fox MP. Retention in HIV care between testing and treatment in subSaharan Africa: a systematic review. PLoS Med. $2011 \mathrm{Jul} ; 8(7): \mathrm{e} 1001056$.

9. Horstmann E, Brown J, Islam F, Buck J, Agins BD. Retaining HIV-infected patients in care: Where are we? Where do we go from here? Clin Infect Dis Off Publ Infect Dis Soc Am. 2010 Mar 1;50(5):752-61.

10. HRSA(Health Resources and Services Administration) CAREAction. The HIV/AIDS Bureau: Addressing the HIV Care Continuum. U.S. Department of Health and Human Services Health Resources and Services Administration, HIV/AIDS Bureau; 2014.
11. National AIDS and STI Control Programme (NASCOP). Kenya AIDS Indicator Survey 2012: Final Report. NASCOP; 2014.

12. Braitstein P, Katshcke A, Shen C, Sang E, Nyandiko W, Ochieng VO, et al. Retention of HIV-infected and HIV-exposed children in a comprehensive HIV clinical care programme in Western Kenya. Trop Med Int Health TM IH. $2010 \mathrm{Jul} ; 15(7): 833-41$.

13. Ministry of Health, National AIDS Control Council (NACC), National AIDS and STI Control Programme (NASCOP). Kenya HIV Estimates Report 2018. NACC; 2018.

14. Ministry of Health, National AIDS and STI Control Programme (NASCOP), National AIDS Control Council (NACC). Kenya HIV County profiles. NACC; 2014.

15. UNICEF (United Nations Children's Fund). Understanding and Improving Viral Load Suppression in Children with HIV in Eastern and Southern Africa. UNICEF; 2021.

16. Wachira J, Middlestadt SE, Vreeman R, Braitstein P. Factors underlying taking a child to HIV care: implications for reducing loss to follow-up among HIV-infected and exposed children. SAHARA-J J Soc Asp HIVAIDS. 2012 Mar 1;9(1):20-9.

17. National AIDS Control Council (NACC). National HIV and AIDS stigma and discrimination index: summary report. NACC; 2015.

18. Braitstein P, Songok J, Vreeman RC, Wools-Kaloustian KK, Koskei P, Walusuna $\mathrm{L}$, et al. 'Wamepotea' (they have become lost): outcomes of HIV-positive and HIVexposed children lost to follow-up from a large HIV treatment program in western Kenya. J Acquir Immune Defic Syndr 1999. $2011 \mathrm{Jul}$ 1;57(3):e40-46.

19. Cargill VA. Linkage, engagement, and retention in HIV care among vulnerable populations: 'I'm sick and tired of being sick and tired". Top Antivir Med. 2013 Oct;21(4):133-7.

20. Mbatia R, Kikaro S, Mgelea E, Nyabukene F, Henjewele C, Temba L, et al. Enhancing HIV Retention and Clinical Outcomes in Tanzania through Pediatric and Adolescent Friendly Services. MEASURE Evaluation Tanzania; 2018.

21. Nasuuna E, Kigozi J, Muwanguzi PA, Babirye J, Kiwala L, Muganzi A, et al. Challenges faced by caregivers of virally non-suppressed children on the intensive 
Ikiara, Eliza Kathure et.al. Retention in HIV care among children aged 0-14 years and the associated family and caregiver factors in Embu County, Kenya.

adherence counselling program in Uganda: a qualitative study. BMC Health Serv Res. 2019 Mar 7;19(1):150.

22. Onubogu CU, Ugochukwu EF. A 17 year experience of attrition from care among HIV infected children in Nnewi South-East Nigeria. BMC Infect Dis. 2021 May 3;21(1):409.

23. Sengayi M, Dwane N, Marinda E, Sipambo N, Fairlie L, Moultrie H. Predictors of loss to follow-up among children in the first and second years of antiretroviral treatment in Johannesburg, South Africa. Glob Health Action. 2013 Jan 24;6:19248.

24. Geng EH, Bangsberg DR, Musinguzi N, Emenyonu N, Bwana MB, Yiannoutsos CT, et al. Understanding reasons for and outcomes of patients lost to follow-up in antiretroviral therapy programs in Africa through a sampling-based approach. J Acquir Immune Defic Syndr 1999. 2010 Mar;53(3):405-11.

25. Reddi A, Leeper SC, Grobler AC, Geddes R, France KH, Dorse GL, et al. Preliminary outcomes of a paediatric highly active antiretroviral therapy cohort from KwaZuluNatal, South Africa. BMC Pediatr. 2007 Mar 17;7:13.

How to cite this article: Ikiara, Eliza Kathure, Orinda, George Owino, Thigiti, Joseph Mwangi. Retention in HIV care among children aged 014 years and the associated family and caregiver factors in Embu County, Kenya. Int J Health Sci Res. 2021; 11(7): 293-302. DOI: https://doi.or/ 10.52403/ijhsr.20210740 